
\title{
3 Research Square \\ The Combined Effects of ENSO and Arctic Oscillation on Wintertime Fog Days in Eastern China
}

\section{Huaying Yu}

Nanjing University of Information Science and Technology

Peng Liu ( $\sim$ liupeng1998@nuist.edu.cn )

Nanjing University of Information Science and Technology

\section{Ying Zhang}

Nanjing University of Information Science and Technology

\section{Research Article}

Keywords: Arctic Oscillation, Fog days, El Niño Southern Oscillation, Early winter, Late winter

Posted Date: February 11th, 2021

DOI: https://doi.org/10.21203/rs.3.rs-183369/v1

License: (c) (i) This work is licensed under a Creative Commons Attribution 4.0 International License. Read Full License

Version of Record: A version of this preprint was published at Theoretical and Applied Climatology on March 29th, 2021. See the published version at https://doi.org/10.1007/s00704-021-03588-y. 


\section{Abstract}

The data of fog days from weather observation stations in China and the NCEP/NCAR re-analysis data from 1954 to 2007 are used to investigate the combined effects of El Niño and Southern Oscillation (ENSO) and Arctic Oscillation (AO) on the number of winter fog days in eastern China. The results show that during El Niño the enhanced low-level southwesterly warm-moist airflow could lead to the temperature rise and humidity increase in eastern China. Note that the rate of humidity increase is faster than the rate of temperature rise, which makes the air in eastern China easy to be saturated. Besides, in winter the North China is dominated by the sinking airflow, so a large-value area of fog days appears in eastern China with the center in North China. While in La Niña years, the atmospheric circulation and its influence on the fog days are the opposite. During the positive AO period, the East Asian trough weakens and the low-level westerly jet moves northward, preventing northwesterly cold air from moving southward. The warming and humidification of North China and the slight temperature drop in South China would cause more fog days in North China and fewer fog days in South China. The effect of negative AO is opposite to that of positive AO. The combined effects of ENSO and AO are far greater than the sum of their individual effects. Under El Niño and positive AO, the number of fog days would increase significantly in North China during the whole winter. Besides, ENSO has greater impacts than AO during early winter and vice versa during later winter.

\section{Introduction}

Fog is a common-seen weather phenomenon in the boundary layer. It refers to the water vapor condensations suspending in the atmosphere, such as water droplets and ice crystals. When the air temperature is close to the dew point, the water vapor in the air could condense into fog. According to the international definition, when the visibility is less than $1 \mathrm{~km}$ it is defined as fog, and when the visibility is more than $1 \mathrm{~km}$ it is defined as mist. Fog is a common disastrous weather in winter in eastern China. Fog damage is mainly reflected in the hazards to traffic safety and health. With the development of the national economy and the improvement of people's quality of life, the losses caused by fog are increasing day by day (Gultepe et al. 2007; Niu et al. 2010a; Cai et al. 2017).

There are many methods to study the climate characteristics of fog, and the most commonly used method is to count the local annual or monthly average fog days. The climatological characteristics of fog in different regions and the annual or seasonal of fog days are mostly analyzed. The results show that fog in China has obvious seasonal variation, and occurs most frequently in winter (Hu et al. 2020; Wang et al. 2005; Sun et al. 2013). In terms of spatial distribution, fog in China is mainly concentrated in the East and Southwest (Yu et al. 2019).

The formation of fog depends on the dynamic (transport and diffusion) and thermal conditions (temperature stratification conducive to water vapor condensation). Zhang et al. (2014) pointed out that the strong cold air activity in January 2013 is less, the East Asian trough is obviously weakened, and the East Asian monsoon is weak. This will lead to the abnormal high pressure of $500 \mathrm{hPa}$ and inhibit the 
development of convection. On the other hand, there is a southerly wind anomaly (water vapor transport in the lower layer) at $925 \mathrm{hPa}$. The weakened wind speed and the obviously high temperature make it easy to form inversion which makes the atmosphere more stable. The stable atmosphere is conducive to the maintenance and development of fog episodes. In general, previous studies show that, fog often occurs when the wind speed is low, the humidity is high and the atmosphere is stable (Sachweh and Koepke 1997; Niu et al.2010b).

Most of the researches are based on the climate factors to discuss the conditions of fog, including the influence of climate factors on dynamic and thermal conditions. In recent years, many scholars have begun to pay attention to the relationship between fog frequency and Arctic Oscillation (AO), Eurasian teleconnection, East Asian winter monsoon (EAWM), El Niño and Southern Oscillation (ENSO) and so on (Niu, et al. 2010b; Yu, et al. 2019; Liu, et al. 2020). Li et al. (2016) found a close relationship between EAWM and fog days in China (Li et al. 2016). Under the background of global warming, the weakening of EAWM increases the frequency of fog days in China (Niu et al. 2010b). As the strongest tropical ocean signal, ENSO has a very important impact on the climate of different seasons in East Asia (Rasmusson and Wallace 1983; Philander 1990).Yu et al. (2019) found that ENSO exerts an important influence on the interannual variation of winter fogs in eastern China by affecting the southwesterly warm-moist airflow from the tropics. AO is the first mode of empirical orthogonal function (EOF) at $1000 \mathrm{hPa}$ or sea level pressure in the northern hemisphere, which is different from the high latitude climate signal of the tropics. AO has a very significant impact on China's winter and spring (Chen et al.2012, 2013; Cohen et al.2014; Gong et al.2001; He et al.2016, 2018; Lee et al.2006; Li et al.2014; Wang et al.2010; Wu et al.2002; Chen et al.2019). Liu et al. (2020) showed that AO affects the East Asian trough, which has a significant impact on the dynamic and thermal conditions of winter fogs in China.

Most of the current studies have focused on the effects of ENSO or AO on precipitation anomalies and other extreme weather events. But, the combined effects of ENSO and AO are likely to produce the different results from those of the single factor (Chen et al., 2013). For example, in January 2008, South China suffered from severe low-temperature rain snow and freezing disaster, which was mainly caused by $A O$ anomaly under the background of La Niña (Wen et al. 2009). When studied the causes of severe winter drought in Yunnan in 2009/2010, Song et al. (2011) found that AO was related to winter precipitation in Yunnan, and was also modulated by ENSO. Zuo (2011) studied the relationship between $A O$ and ENSO and its impact on the climate anomalies in China. In the different phase combinations of $\mathrm{AO}$ and ENSO, the precipitation anomaly in Southeast China is mainly controlled by ENSO. However, AO obviously adjusts the path of water vapor transport anomaly and the location of precipitation anomaly.

However, the combined effects of ENSO and AO on winter fog days in China are not clear. Therefore, in this paper the interannual variability of winter fogs in eastern China is aimed. We attempt to explain how ENSO and AO jointly affect the number of fog days in eastern China and which of them is more important. The remainder of this paper is organized as follows. Section 2 describes the data and methodology. In section 3, a special attention will be paid to the distinctive difference of fog frequency between early and late winter. Meanwhile, the climatological characteristics of fog days in eastern China 
are presented, and the major environmental factors controlling the fog formation are also discussed. In section 4, we examine the composite patterns of fog days in early and late winter during El Niño, La Niña, +AO and -AO phases, and the associated large-scale dynamic and thermodynamic variables. Besides, physical mechanisms responsible for the distinctive patterns in early and late winter are also discussed in section 4. In section 5, we attempt to explain how ENSO and AO jointly affect the number of fog days in eastern China and which of them is more important. Finally, a summary and discussions are given in section 6.

\section{Data And Methods}

Previous studies have shown that the frequency of fog days in China is variable both in time and space. Fog events may occur frequently or rarely in a given year (Syed et al., 2012). The fog days were obtained from the surface observation dataset of 503 weather stations in China. From daily weather station records during the period of 1954-2007, we calculated fog days at each station for early winter (November and December, hereinafter referred to as ND) and late winter (January and February, hereinafter referred to as JF). The monthly data after interpolation with a spatial resolution of $1^{\circ} \times 1^{\circ}$ was adopted. To highlight the characteristics of fog days in eastern China, the mapping range of fog days was set as $\left(70-140^{\circ} \mathrm{E}, 15-55^{\circ} \mathrm{N}\right)$.

The National Centers for Environmental Prediction/National Center for Atmospheric Research (NCEP/NCAR) monthly reanalysis data was used in this paper, including wind, geopotential height, specific humidity, relative humidity and temperature. The dew point temperature could be calculated based on relative humidity and temperature, and then the depression of the dew point could be calculated based on the temperature and the dew point temperature. The globe data is from 1954 to 2007, with a spatial resolution of $2.5^{\circ} \times 2.5^{\circ}$.

In order to analyze the effects of ENSO and AO, we defined the El Niño events (Table 2, Positive ESNO), the $+\mathrm{AO}$ events (Table 3 and 4, Positive AO), the La Niña events (Table 2, Negative ESNO) and the -AO events (Table 3 and 4, Negative AO) according to the maximum and minimum values of the multivariate ENSO Index (MEI.v1) and a winter AO Index (NOAA Climate Prediction Center). Finally, fourteen El Niño events, fourteen La Niña events, fourteen +AO events and fourteen - $A O$ events were obtained. In this paper, the composite analysis method was used to explore the climate background during the years with more winter fog days, as well as that during the years with less winter fog days. Based on the observation data of fog days and the reanalysis data, the effects of ENSO and AO on the wintertime fog days in east China were discussed.

Moreover, the influences of ENSO and AO on the meteorological conditions (circulations, temperature, water vapor, etc.) were also analyzed in this paper. Eastern China refers to $\left(110-120^{\circ} \mathrm{E}, 20-40^{\circ} \mathrm{N}\right)$; North China refers to $\left(110-120^{\circ} \mathrm{E}, 30-40^{\circ} \mathrm{N}\right)$; South China refers to $\left(110-120^{\circ} \mathrm{E}, 20-30^{\circ} \mathrm{N}\right)$, and the Yangtze River basin is around $30^{\circ} \mathrm{N}$. 


\section{Characteristics Of Fog Days In Eastern China, And Their Relationships With Enso And Ao}

Fig. 1 shows that from November to February, the number of fog days in eastern China is over 10; the number of fog days in the Yangtze River basin can reach more than 15, and in parts of Southwest and South China, the number can reach more than 20. From Fig. 1b, it can be seen that wintertime fog days account for more than $40 \%$ of the annual fog days in eastern China. While in North China, Southwest China, the middle reaches of Yangtze River basin, and some parts of South China the ratio can even reach $50 \%$ or more. Therefore, it is necessary to analyze the fog days in eastern China in wintertime where and when the fog occurs frequently.

Previous studies (Yu et al. 2019, Liu et al. 2020) have shown that ENSO and AO are important influence factors on the fog days. But, are there any differences between ENSO and AO? Besides, previous studies also showed that the ENSO impacts in early winter and late winter are quite different, so it is necessary to divide the wintertime into early winter (November-December; abbreviated as ND) and late winter (January-February; abbreviated as JF). However, are the effects of AO on fog days different between in ND and in JF? To answer this question, Fig. 2 discusses the performance of the two indexes in ND and JF.

To remove the effect of inter-decadal variations and trends, the 9-point smoothing result is subtracted from the original index, and thus the inter-annual signal is reserved. Fig. 2a and Fig. 2b show the ENSO and AO indexes (1954-2007) in ND and JF, respectively. Their autocorrelation coefficients can reach 0.96 and 0.30 , respectively. The ENSO index has very strong inter-annual variation, and the auto-correlation between the ENSO indexes in ND and JF is also large. But, the AO index is an atmospheric signal with weak persistence, so the auto-correlation of $A O$ index between ND and JF is weak. However, there is a significant difference in the strength of the inter-annual oscillation of the AO index in ND before and after 1980. It is weak before 1980 and strong after 1980 . While the AO index in JF presents significant interannual variation over the whole period.

Fig. 2c shows the auto-correlation coefficients of the two indexes in adjacent months. It can be found that the auto-correlation coefficients of the ENSO index are all above 0.9, with the largest in Oct-Feb, especially in ND when it reaches the peak of 0.99 . But, the persistence of high auto-correlation is weak, and the auto-correlation decreases after winter. So, it is also an obstacle for ENSO forecasting. Since the ENSO signal has a better persistence in winter, the ENSO index in ND is used as an influencing factor on fog days in eastern China. It can be seen in Fig. 1c that the monthly persistence of the AO-index autocorrelation is weak, and it only becomes a little persistent in winter and spring. Because of the weak persistence, it is necessary to use AO indexes in ND and JF respectively to study its impact on fog days. The correlation coefficient of $A O$ index between ND and JF is 0.3 , which means that on a bimonthly average, it is and would be persistent. It can be seen from Table 1 that most of the correlation coefficients have not passed the significance test. AO is positively correlated to ENSO in ND, but negatively correlated to ENSO in JF, indicating that the relationship between AO and ENSO is changed in ND and JF. Especially 
in JF, the AO is significantly related to ENSO, possibly due to the fact that ENSO has an effect on the atmospheric signal $A O$ after reaching its peak in the winter and receives the response from $A O$. Therefore, from the results of previous studies (Yu et al. 2019, Liu et al. 2020) and the above relationship between ESNO and AO, the impact of the AO and ENSO indexes on fog days in eastern China in winter will be studied.

In this section, based on the ENSO index, fourteen El Niño years and fourteen La Niña years are selected. Fig. 3a and Fig. 3b respectively show the difference of fog days between El Niño years and La Niña years in ND and JF in eastern China. It can be seen that the difference of the fog days between ND and JF is huge in El Niño or La Niña years. In ND, fog days are more frequent in eastern China, centered in North China, while they are less frequent in JF. Fig. $3 \mathrm{c}$ and Fig. $3 \mathrm{~d}$ are the difference of fog days between AO positive anomaly $(+A O)$ years and $A O$ negative anomaly $(-A O)$ years in eastern China in ND and JF, respectively. In $+A O$ years, the distribution of fog days in ND and JF are basically the same, with more fog days in North China and less fog days in South China. In order to discuss the effects of ENSO and AO more fairly, the 14-year composite data is used for each analysis. But, the influence of $A O$ on fog days is more significant in JF than in ND. The comparison reveals that ENSO has greater impact on fog days in ND (Fig. 3a), while AO has greater impact in JF (Fig. 3d).

Figure 4 shows the standard deviation distribution of winter fog days in eastern China in ND and JF during 1954-2007. It is shown that the whole eastern China has the fog days of more than 2-3 days, with the number in ND larger than in JF. North China, Southwest China and South China are the regions with large variation of the fog days, which can reach over 4 days in ND and over 3 days in JF.

Further comparison between the two factors show that, in ND the effects of ENSO in North China can account for over $40 \%$ of the standard deviation of fog days, and in JF its effects on most parts of the eastern China is basically less than $20 \%$. In ND, AO in North China can explain more than $20-30 \%$ of the standard deviation of fog days, but it is weaker in South China. In JF, the AO impact is significantly stronger and can reach over $40 \%$ in North China and $20-30 \%$ in South China. In the following, the impacts of ENSO and AO on fog days will be analyzed through the atmospheric circulations.

\section{The Relationships Between The Fog Days In Eastern China And The Atmospheric Circulations In The Years Of Enso Or Ao}

The latitude-vertical profiles of the water vapor and wind fields (Fig. 5) show that water vapor is more affected by ENSO and less affected by AO. From the climatology of vertical velocity, the North China is in the region of sinking airflow, and the atmospheric stratification is stable there. So, the key to the occurrence of fog days is whether the water vapor supersaturation could occur. Under the influence of El Niño, $25^{\circ} \mathrm{N}$ is the center of the anomalous increase in water vapor during ND. In $30-40^{\circ} \mathrm{N}$, the water vapor increase and the sinking airflow are conducive to the increase of fog days in North China. While in JF, the positive anomaly of moisture weakens in $25^{\circ} \mathrm{N}$, so the number of fog days does not increase significantly in eastern China, and even a decrease occurs in North China. During ND and JF, under the positive AO 
anomaly there is an increase of humidity in the north of $30^{\circ} \mathrm{N}$, so the number of fog days increases in North China; while in South China, there is a decrease in both water vapor and fog days.

Water vapor supersaturation is a necessary condition for the occurrence of fog. Seen from the above figures, in the case of positive anomaly of ENSO and AO, the warming and wetting occur simultaneously. Therefore, to achieve the water-vapor supersaturation, the increasing rate of water-vapor must be faster than that of temperature, and we could not just consider the variation of water vapor or temperature.

From Fig. 6, it can be seen that the areas with negative dew-point deficit (T-Td) are easy to supersaturate. When El Niño occurs, the anomalous warm-wet airflow transports large amount of water vapor northward, and the transport is large in ND and slightly less in JF. Due to the faster increase in water vapor and the slower increase in temperature in ND, significant negative dew-point deficit appears in $20-50^{\circ} \mathrm{N}$ in eastern China (Fig. 6a), leading to significant increase of fog days (Fig. 3a). While in JF, the transport of anomalous warm-wet airflows to the north is slightly weaker. Although there is a significant increase in temperature, the increase in water vapor is slower and negative dew-point deficit only occurs in $20-30^{\circ} \mathrm{N}$. Accompanied by a weak downdraft, the number of fog days increases slightly in that region. $\ln 35^{\circ} \mathrm{N}$ of North China, the dew-point deficit reaches the positive maximum value of $0.6 \mathrm{~K}$ (Fig. $6 \mathrm{~b}$ ), and the number of fog days decreases due to the drier atmosphere.

When positive $\mathrm{AO}$ anomaly occurs, there is a significant temperature increase in North China due to the weakening of the East Asian trough, while the water vapor increase is insignificant. During ND, although the increase in water vapor is weak, there are some areas where the increase of water vapor is faster than that of temperature. In $32-42^{\circ} \mathrm{N}$, with negative dew-point deficit and sinking airflows, more fog days are likely to occur. While in $20-30^{\circ} \mathrm{N}$, the vertical air motion is dominated by updrafts and the dew-point deficit is positive, so the fog days are fewer. In JF, due to the northward movement of the warming center, most parts of eastern China are in a negative temperature anomaly. But, the water vapor is increased in $20-40^{\circ} \mathrm{N}$, and then a large-value area of negative dew-point deficit centered in North China appears. Besides, the updrafts and downdrafts are bounded by $30^{\circ} \mathrm{N}$. There is a very significant increase of fog days to the north of $30^{\circ} \mathrm{N}$ and an increase of precipitation near $30^{\circ} \mathrm{N}$, while a decrease of fog days on the south of $30^{\circ} \mathrm{N}$.

Fig. 7a and Fig. 7b show the difference of composite $850 \mathrm{hPa}$ wind and specific humidity anomaly between El Niño and La Niña years in ND and JF. As can be seen, the ENSO event occurs with an anomalous warm-wet southwesterly airflow, which is larger in ND and slightly smaller in JF. In ND, there is a significant anomalous high in Japan at the $500 \mathrm{hPa}$ height field, accompanied by stronger anomalous $850 \mathrm{hPa}$ southwesterly airflows, leading to significant warming and wetting in eastern China. However, in ND the wetting is stronger (Fig. 7a) and the warming is weaker (Fig. 8a), so there is a significant increase in the precipitation in eastern China where the center of anomalous precipitation coincides with the center of the anomalous water-vapor increase (Fig. 9a). Then the anomalous sinking airflow would occur on the north of the $27^{\circ} \mathrm{N}$ precipitation center, causing more fog days in North China. In JF, however, the anomalous southwesterly airflow is weaker (Fig. 7b), so is the ability of the warm-wet airflow to advance 
northward. At $500 \mathrm{hPa}$ height field, there is an anomalous high pressure in Siberia, resulting in significantly higher warming in eastern China than in ND (Fig. 8b). Thus, the large-value center of the precipitation anomaly in Fig. 9b appears more southerly (Fig. 9b). Around $20^{\circ} \mathrm{N}$ in North China, the increasing rate of warming is higher than wetting, so the supersaturation is less likely to occur, resulting in less fog days.

When a positive $\mathrm{AO}$ anomaly occurs, the East Asian trough would weaken, and a significant increase in the height field and a temperature increase would appear in North China, but the water-vapor increase is not significant. During ND, on the north of $30^{\circ} \mathrm{N}$ (Fig. 7c), there are anomalous easterly wind that are actually the weakened climatic low-level jet, resulting in a water-vapor increase in North China.

Anomalous high pressure occurs at $50^{\circ} \mathrm{N}$ in eastern China at $500 \mathrm{hPa}$, and there is an anomalous warm center in the low levels (Fig. 6c), with significant warming in eastern China (Fig. 8c). Although there are few areas with significant water-vapor increase, some areas in $32-42^{\circ} \mathrm{N}$ where the water-vapor increases faster than temperature and the downdraft prevails, are prone to have more fog days.

As can be seen in Fig. $6 \mathrm{c}$, there is a negative dew-point deficit at $20^{\circ} \mathrm{N}$ and $35^{\circ} \mathrm{N}$, indicating that both regions are prone to supersaturation, which correspond well to the two precipitation centers (Fig. 9c). The descending motion in $35^{\circ} \mathrm{N}$ of North China is still significant, so the fog days there increase. In JF, the weakening of the East Asian trough is more pronounced, the anomalous easterly wind is stronger, and the low-level jet is more intense. As a result, the water-vapor anomaly in North China is more significant (Fig. 7d). Although the warming is stronger (Fig. 8d), the warming center has moved northward, and most of eastern China is of a negative temperature anomaly. In $30^{\circ} \mathrm{N}$, the increased moisture and supersaturation cause more precipitation in the Yangtze River basin (Fig. 9d). The precipitation increase leads to the temperature decrease in the lower atmosphere. The supersaturation in North China interacts with the downdrafts, and as a result the number of fog days increases significantly in North China. Nevertheless, South China has a significant increase of precipitation and strong updrafts, which results in a decrease of fog days in South China.

\section{The Combined Effects Of Enso And Ao On Wintertime Fog Days In Eastern China}

To further illustrate the combined effects of ENSO and AO on fog days in eastern China, we select the AO positive years out of the fourteen El Niño years and fourteen La Niña years. Then, the composite analysis is given in Fig. 10 and Fig. 11. The fog days during El Niño years (Fig. 10) are almost half of the difference of composite fog days between El Niño and La Niña years (Fig. 3). In ND, the fog days affected only by El Niño are compared with the fog days affected by El Niño and positive AO anomaly (Figs. 10a, $10 \mathrm{c}$ and $10 \mathrm{e}$ ). It can be seen that there are both many fog days in North China under the two situations. However, affected by the positive $\mathrm{AO}$ anomaly, insignificantly less fog days appear in South China. Then the fog days affected by La Niña alone are compared with the fog days affected by La Niña and positive $\mathrm{AO}$ anomaly (Figs. 11a and 11e). The distributions of fog-day anomaly are similar in the two cases, with fog days less frequent in eastern China. The above analyses show that in ND, the influence of ENSO is 
dominant, and the influence of $\mathrm{AO}$ on fog days is limited. The combined effects of ENSO and $\mathrm{AO}$ are far greater than the sum of their individual effects (Figs. 10a, 10c, 10e, 11a, 11c and 11e).

In JF, the fog days affected only by El Niño and the fog days affected by both El Niño and positive AO anomaly are compared (Figs. 10b, 10d and 10f). It can be seen that in the two cases, North China has more fog days and South China has less fog days. The distribution of fog days affected by both El Niño and positive $A O$ anomaly is very similar to that affected by only the positive $A O$ anomaly. Then, the distributions of fog days affected by La Niña alone, by the positive $A O$ anomaly alone, and affected by both La Niña and positive AO anomaly are compared (Figs. 11b, 11d and 11f). It can be seen in Fig. $11 \mathrm{f}$ that, in eastern China, there are more fog days in North China and fewer fog days in South China, but this phenomenon is not significant. The above analyses show that in JF, AO is basically dominant, and the effect of ENSO on fog days is limited. Especially in JF, the combined effects of ENSO and AO are very obvious. Whether in EI Niño or La Niña years, the combined effects of ENSO and AO are far greater than individual AO effects in Northern China (Figs. 10d, 10f, 11d and 11f).

In ND in the years of both El Niño and positive AO anomaly (Fig. 12a), the Japanese high at $500 \mathrm{hPa}$ is strengthened, and there is a warming in eastern China. The southwesterly warm-moist airflow could bring abundant water vapor to eastern China (Fig. 13a). However, the supersaturation and a negative dew-point deficit appear in South China (Fig. 14a). With the strong updrafts, heavy precipitation events frequently occur in South China. However, the supersaturation near $40^{\circ} \mathrm{N}$ is accompanied with the sinking airflow, which increases the fog days in North China. The effect of the positive AO anomaly is the warming in eastern China. When the water vapor is constant, fewer areas are prone to supersaturation under the warming. Thus the area with frequent fog days in eastern China is reduced. When El Niño and positive AO anomaly work together in JF, the Siberian high anomaly enhances due to the strong influence of positive $\mathrm{AO}$ anomaly (Fig. 12b). Although in El Niño years there is a weakening of the southwesterly airflow during $\mathrm{JF}$, the southwesterly flow could enhance anomalously due to the positive AO anomaly (Fig. 15b). Consequently, the water-vapor increase is very significant, and the wetting is more rapid than warming in North China. As a result the supersaturation is more likely to occur in North China (Fig. 14b). Accompanied with the sinking airflow, the fog days of North China increase significantly. Besides, the strong southwesterly moisture transport (Fig. 13b) increases the heavy precipitation in South China and reduces the possibility of fog-day occurrence.

In ND in the years of both La Niña and positive AO anomaly, although the high pressure anomaly and temperature increase occur in the areas north of $40^{\circ} \mathrm{N}$ (Fig. 12c), the temperature in most parts of eastern China is lower and the southwesterly warm-wet airflow changes to negative anomaly. With the cold-dry air from the north moving southward, the water vapor is in a negative anomaly (Fig. 13c), and it is indicated that the atmosphere is getting colder and drier (Fig. 15c). Moreover, the dew-point deficit in most parts of eastern China is in a positive anomaly (Fig. 14c), and the air is unlikely to supersaturate. Therefore, the fog days in eastern China are reduced. In contrast, the positive AO anomaly in ND has basically no influence on the areas south of $40^{\circ} \mathrm{N}$. In JF of the La Niña years, the anomalous height centered on Japan at $500 \mathrm{hPa}$ increases, and the East Asian trough weakens significantly (Fig. 12d). Under the influence of 
the strong $\mathrm{AO}$ anomaly in $\mathrm{JF}$, the anomalous southeasterly wind in eastern China strengthens, and brings an anomalous increase of water vapor (Fig. 15d). Besides, the La Niña is conducive to the cooling in eastern China. The decrease in temperature and the increase in water vapor cause a negative anomaly in dew-point deficit over a wide area of eastern China (Fig. 14c). Accompanied with the sinking airflow in North China, a large-value center of fog days then appears at $35^{\circ} \mathrm{N}$. Yet with the strong ascending movement (Fig. 13d), South China becomes the large-value center of precipitation, without significant change of fog days. Therefore, in La Niña years the significant difference of fog days between ND and JF is mainly caused by the intensity of $\mathrm{AO}$.

\section{Discussion And Conclusions}

In this paper, the seasonal characteristics and spatial distribution of wintertime fog days in eastern China are analyzed, and the individual and combined effects of ENSO and AO on the meteorological background fields (circulation field, temperature, water vapor, etc.) related to the fog days in eastern China. The conclusions are as follows.

First, the fog days in eastern China are more frequent in winter, accounting for more than $40-50 \%$ of the whole year, so it is important to study the fog days in winter. As an important tropical climatic impact factor, ENSO plays significantly different roles during ND and JF in eastern China, affecting the extent and intensity of fog days. Besides, the impacts of $A O$ are also distinctly different in ND and JF. Therefore, wintertime here is divided into ND and JF.

During the ND of the ENSO positive phase, fog days are frequent in eastern China, and the main largevalue area is in North China. During the JF of the ENSO positive phase, ENSO has little influence on the fog days in eastern China, and the number of fog days in North China even decreases slightly. During the ND of the ENSO positive phase, there is a stronger southwesterly warm-wet airflow, which increases the temperature and humidity in eastern China, and the increasing rate of wetting is faster than warming. Thus, the whole eastern China is prone to reach water vapor supersaturation. In South China, there are strong upward motions and precipitation positive anomalies. However, in North China, there are more fog days due to the climatic sinking airflow and the water vapor supersaturation. In JF, the southwesterly warm-wet airflow is weaker. Although there is precipitation in South China, the intensity is weaker than that in ND. Besides, the warm-wet air flow is difficult to move northward to North China, so there are slightly less fog days.

AO has significant effects on fog days in eastern China, both in ND and JF. In positive phase of AO, the number of fog days increases in North China and decreases in South China, and this phenomenon is more pronounced in JF than in ND. Meanwhile, with the polar pressure weakening, the middle and lowlevel pressure in East Asia anomalously enhances. The East Asian trough weakens, and the westerly lowlevel jet moves northward, preventing northwesterly cold air from moving southward. Warming and wetting in eastern China lead to limited regions prone to water vapor supersaturation, which are mainly concentrated in North China. Thus fog days increase in North China. The increase in water vapor is 
limited, and the overall precipitation anomaly in eastern China is smaller than the precipitation anomaly induced by ENSO. The water vapor in South China decreases, and fog days become fewer in South China. In contrast, the AO positive anomaly is more pronounced in ND than in JF. With the weaker East Asian trough and more significant warming and wetting in North China, more areas could reach water-vapor supersaturation, and the precipitation anomaly center shifts northward. Therefore, more fog days appear in North China.

To analyze the combined effects of ENSO and AO on fog days in eastern China, the AO positive anomaly years in the ENSO event are selected for discussion. It is found that during ND, in both El Niño years and La Niña years, the distribution pattern of fog days affected by El Niño or La Niña alone in eastern China are basically similar to that of those affected by positive AO and El Niño or positive AO and La Niña. There are more fog days in El Niño years and fewer in La Niña years in eastern China. Moreover, AO positive anomaly in El Niño is taken as an example. El Niño is conducive to water vapor increase, and the warming is more significant in North China affected by positive AO. It reduces the possibility of water vapor supersaturation, and there is a slight decrease in fog days in North China than the years affected by the El Niño alone. Overall, the fog days in ND are influenced mainly by ENSO. During JF, under the AO positive anomaly, in both El Niño years and La Niña years, the fog-day distribution patterns are similar to those of fog days affected only by positive $A O$ in eastern China. There are more fog days in North China and fewer fog days in South China. Then, the AO positive anomaly in La Niña year is taken as an example. Although La Niña is conducive to the reduction of water vapor and temperature in eastern China, the stronger positive AO in JF significantly weakens the East Asian trough and moves the westerly low-level jets northward. In eastern China, wetting and warming are dominant. Therefore, there is a significant increase of fog days in North China. Overall, the fog days in JF are influenced mainly by AO. The combined effects of ENSO and AO are far greater than the sum of their individual effects (Fig. 10 and Fig. 11), especially in JF. Whether in El Niño or La Niña years, the combined effects of ENSO and AO are far greater than individual AO effects in Northern China (Figs. 10d, 10f and 11f). The enhanced warmmoist airflow in JF of El Niño years could lead to the water-vapor increase in Northern China, and in JF of La Niña years there are more fog days in Northern China (Yu et al. 2019). When combined with the positive AO, both these two situations could lead to the increase of fog days in Northern China. So, the combined effects of ENSO and AO are significant.

Above all, ESNO's influences on fog days are mainly through the transport of water vapor from low latitudes to mid- high latitudes. While AO influences fog days mainly by affecting the height field of the large East Asian trough and the temperature distribution in the lower atmosphere. The effects of ENSO mainly act in ND, while the effects of AO mainly act in JF. Under the combined effects of ESNO and AO, the fog days in eastern China could be significantly affected.

\section{Declarations}

Author Contributions: Conceptualization, P.L.; methodology, software, validation, P.L., and H.Y.; formal analysis, investigation, data curation, writing-original draft preparation, visualization, P.L.; writing-review 
and editing, P.L., H.Y., Y.Z.; resources, supervision, funding acquisition, project administration, H.Y. All authors have read and agreed to the published version of the manuscript.

Funding: This work is jointly supported by China National Key R\&D Program 2016 YFA0600402 and National Natural Science Foundation of China under grant 41605045.

Acknowledgments: We thank Nanjing Hurricane Translation for reviewing the English language quality of this paper.

Data: The station data used in this study are provided by China Meteorological Administration. AO index is available from https://www.cpc.ncep.noaa.gov/products/precip/CWlink/daily_ao_index/ao.shtml. ENSO index is available from https://psl.noaa.gov/enso/mei.ext/. NCEP/NCAR re-analysis data is available from https://psl.noaa.gov/data/gridded/data.ncep.reanalysis.pressure.html.

Conflicts of Interest: The authors declare no conflict of interest.

\section{References}

Cai,W.; Li,K.; Liao,H.; Wang,H.J.; Wu,L.X.(2017). Weather conditions conducive to Beijing severe haze more frequent under climate change. Nature Climate Change, 7(4), 257-262.

https://doi.org/10.1038/NCLIMATE3249

Chen, S.F.; Song, L.Y. (2019). Recent Strengthened Impact of the Winter Arctic Oscillation on the Southeast Asian Surface Air Temperature Variation. Atmosphere, 10, 164.

https://doi.org/10.3390/atmos10040164

Chen, W.; Zhou, Q. (2012). Modulation of the Arctic Oscillation and the East Asian winter climate relationships by the 11-year solar cycle. Advances in Atmospheric Sciences, 29, 217-226.

https://doi.org/10.1007/s00376-011-1095-3

Chen, W. ; Lan, X. Q. ; Wang, L. ; Ma, Y. (2013) The combined effects of the ENSO and the Arctic Oscillation on the winter climate anomalies in East Asia. Chinese Science Bulletin, 58, 634-

641.https://doi.org/10.1007/s11434-012-5654-5 (in Chinese)

Cohen, J.; Screen, J.A.; Furtado, J.C.; Barlow, M.; Whittleston, D.; Coumou, D.; Francis, J.; Dethloffff, K.; Entekhabi, D.; Overland, J.; et al. (2014). Recent Arctic amplification and extreme mid-latitude weather. Nature Geoscience , 7, 627-637. https://doi.org/10.1038/ngeo2234

Gong, D.Y.; Wang, S.W.; Zhu, J.H. (2001). East Asian winter monsoon and arctic oscillation. Geophysical Research Letters, 28, 2073-2076. https://doi.org/10.1029/2000GL012311

Gultepe, I.; Tardif, R.; Michaelides, S.; Cermak, J.; Bott, A.; Bendix, J.; Muller, M.D.; Pagowski, M.; Hansen, B.; Ellrod, G. et al. (2007).Fog research: A review of past achievements and future perspectives. Pure and Applied Geophysics, 164, 1121-1159. https://doi.org/10.1007/978-3-7643-8419-7_3 
He, S.P.; Wang, H. (2016). Linkage between the East Asian January temperature extremes and the preceding Arctic Oscillation. International Journal of Climatology, 36, 1026-1032.

https://doi.org/10.1002/joc.4399

He, S.P.; Gao, Y.; Li, F.; Wang, H.; He, Y. (2018). Impact of Arctic Oscillation on the East Asian climate: A review. Earth Science Reviews , 164, 48-62. https://doi.org/10.1016/j.earscirev.2016.10.014

Hu S., W. Zhang, A. Turner, J. Sun. 2020: How does El Nino-Southern Oscillation affect winter fog frequency over eastern China? Climate Dynamics, 54, 1043-1056. https://doi.org/10.1007/s00382-01905043-1

Li, Y.; Li, F.S.; Li, C. et al. (2019). Impact of the Eurasian Teleconnection on the Interannual Variability of Haze-Fog in Northern China in January[J]. Atmosphere, 10, 113. https://doi.org/10.3390/atmos10030113

Liu, P.; Tang, M.Y.; Yu, H.Y.; Zhang, Y. (2020). Influence of Arctic Oscillation on Frequency of Wintertime Fog Days in Eastern China. Atmosphere, 11, 162. https://doi.org/10.3390/atmos11020162

Li, Q.; Zhang, R.H.; Wang, Y. (2016). Interannual variation of the wintertime fog-haze days across central and eastern China and its relation with East Asian winter monsoon. International Journal of Climatology, 36, 346-354. https://doi.org/10.1002/joc.4350

Lee, H.S.; Jhun, J.G. (2006). Two types of the Asian continental blocking and their relation to the east Asian monsoon during the boreal winter. Geophysical Research Letters, 33, L22707.

https://doi.org/10.1029/2006GL027948

Li, F.; Wang, H.; Liu, J. (2014). Short Communication The strengthening relationship between Arctic Oscillation and ENSO after the mid-1990s International Journal of Climatology, 34, 2515-2521.

Niu, S.J.; Lu, C.S.; Yu, H.Y.; Zhao, L.; Lv, J.(2010a).Fog research in China: An overview. Advances in Atmospheric Sciences, 27, 639-662. https://doi.org/10.1007/s00376-009-8174-8

Niu, F.; Li, Z.; Li, C.; Lee, K.H; Wang, M. (2010b). Increase of wintertime fog in China: potential impacts of weakening of the Eastern Asian monsoon circulation and increasing aerosol loading. Journal of Geophysical Research, 115, D00K20. https://doi.org/10.1029/2009JD013484

Philander, S.G.H. (1990). El Nino, La Nina, and the Southern Oscillation. Academic Press, Cambridge, United States, 293.

Rasmusson, E.M.; Wallace, J. (1983). M. Meteorological aspects of the El Niño/southern oscillation. Science, 222, 1195-1202.

Sachweh, M.; Koepke, K.P. (1997). Fog dynamics in an urbanized area. Theoretical and Applied Climatology, 58, 87-93. https://doi.org/10.1007/BF00867435 
Song, J. ; Yang, H. ; Li, C. Y. (2011) A Further Study of Causes of the Severe Drought in Yunnan Province during the 2009/2010 Winter. Chinese Journal of Atmospheric Sciences, 35, 1009-1019. (in Chinese)

Sun, Y.; Ma, Z.; Niu, T.; Fu, R.; Hu, J. (2013). Characteristics of climate change with respect to fog days and haze days in China in the past 40 years. Climate Environment Research, 18, 397-406. (in Chinese) https://doi.org/10.3878/j.issn.1006-9585.2013.12170

Syed, F.S.; Kornich, H.; Tjernstrom, M. (2012). On the fog variability over South Asia. Climate Dynamics, 39, 2993-3005. https://doi.org/10.1007/s00382-012-1414-0

Wang, L.P.; Chen, S.Y.; Dong, A.X. (2005). The distribution and seasonal variations of fog in China. Acta. Geogr. Sin, 60 (4), 134-139. (in Chinese) https://doi.org/10.3969/j.issn.1009-637X.2006.03.010

Wang, L.; Chen, W. (2010). Downward Arctic Oscillation signal associated with moderate weak stratospheric polar vortex and the cold December 2009.Geophysical Research Letters, 37, L09707. https://doi.org/10.1029/2010GL042659

Wu, B.Y.; Wang, J. (2002). Winter Arctic Oscillation, Siberian High and East Asian winter monsoon.Geophysical Research Letters, 29, 1897. https://doi.org/10.1029/2002GL015373

Wen, M.; Yang, S.; Kumar, A. et al. (2009). An analysis of the large-scale climate anomalies associated with the snowstorms affecting China in January 2008[J]. Mon Weather Rev, 137, 1111-1131.

Yu, H.Y.; Tim Li; Liu, P. (2019). Influence of ENSO on frequency of wintertime fog days in Eastern China[J]. Climate Dynamics, 52, 5099-5113. https://doi.org/10.1007/s00382-018-4437-3

Zhang, R.H.; Li, Q.; Zhang, R.N. (2014). Meteorological conditions for the persistent severe fog and haze event over eastern China in January 2013. China Earth Science, 57, 26-35.

https://doi.org/10.1007/s11430-013-4774-3

Zuo, J.Q. (2011). The relationship between AO_NAO and ENSO and its impact on the climate anomalies in China [D]. Gansu: Lanzhou University. (in Chinese)

\section{Tables}

Table 1. The correlation between ENSO wintertime index and AO index in different months.* represents the values exceeding the $90 \%$ confidence level.

\begin{tabular}{|lllllll|}
\hline AO & Nov & Dec & ND & Jan & Feb & JF \\
\hline ENSO & 0.08 & 0.11 & 0.13 & -0.20 & -0.18 & $-0.23^{*}$ \\
\hline
\end{tabular}

Table 2. Classification of anomalous years based on the phases of wintertime ENSO index during 19542007. 
Positive ENSO (El Niño)

1957/1958, 1958/1959, 1963/1964, 1965/1966, 1972/1973, 1977/1978, 1982/1983, 1986/1987, 1987/1988, 1991/1992, 1994/1995, 1997/1998, $2002 / 2003,2006 / 2007$
Negative ESNO (La Niña)

1954/1955,1955/1956, 1956/1957, 1964/1965, 1970/1971,1973/1974, 1975/1976, 1984/1985, 1988/1989, 1995/1996, 1998/1999, 1999/2000, 2000/2001, 2005/2006

Table 3. Classification of anomalous years based on the phases of wintertime AO index during 19542007 (Nov-Dec).

\section{Positive AO}

1971/1972, 1972/1973, 1975/1976, 1978/1979, 1979/1980, 1982/1983, 1988/1989, 1991/1992, $1992 / 1993,1994 / 1995,1999 / 2000,2003 / 2004$, 2004/2005, 2006/2007
Negative AO

1955/1956, 1968/1969, 1969/1970, 1976/1977, $1980 / 1981,1981 / 1982,1985 / 1986,1987 / 1988$, 1989/1990, 1995/1996, 1996/1997, 2000/2001, $2002 / 2003,2005 / 2006$

Table 4. Classification of anomalous years based on the phases of wintertime AO index during 19542007 (Jan-Feb).

\section{Positive AO}

$1956 / 1957,1958 / 1959,1961 / 1962,1963 / 1964$ $1966 / 1967,1972 / 1973,1974 / 1975,1975 / 1976$ $1983 / 1984,1981 / 1982,1988 / 1989,1989 / 1990$, $1999 / 2000,2001 / 2002$

\section{Negative AO}

$1957 / 1958,1959 / 1960,1962 / 1963,1965 / 1966$ $1968 / 1969,1969 / 1970,1976 / 1977,1977 / 1978$ 1984/1985, 1985/1986, 1986/1987, 1993/1994, $1997 / 1998,2003 / 2004$

Table 5. Classification of anomalous years based on the phases of wintertime +AO index(EI Nino, La Nina) during 1954-2007.

\begin{tabular}{|llll|}
\hline & Nov-Dec & Jan-Feb \\
\hline +AO El Nino & $1972,1982,1994,2006$ & $1959,1964,1973$ \\
\hline +AO La Nina & $1975,1988,1999$ & $1957,1976,1989,2000$ \\
\hline
\end{tabular}

\section{Figures}



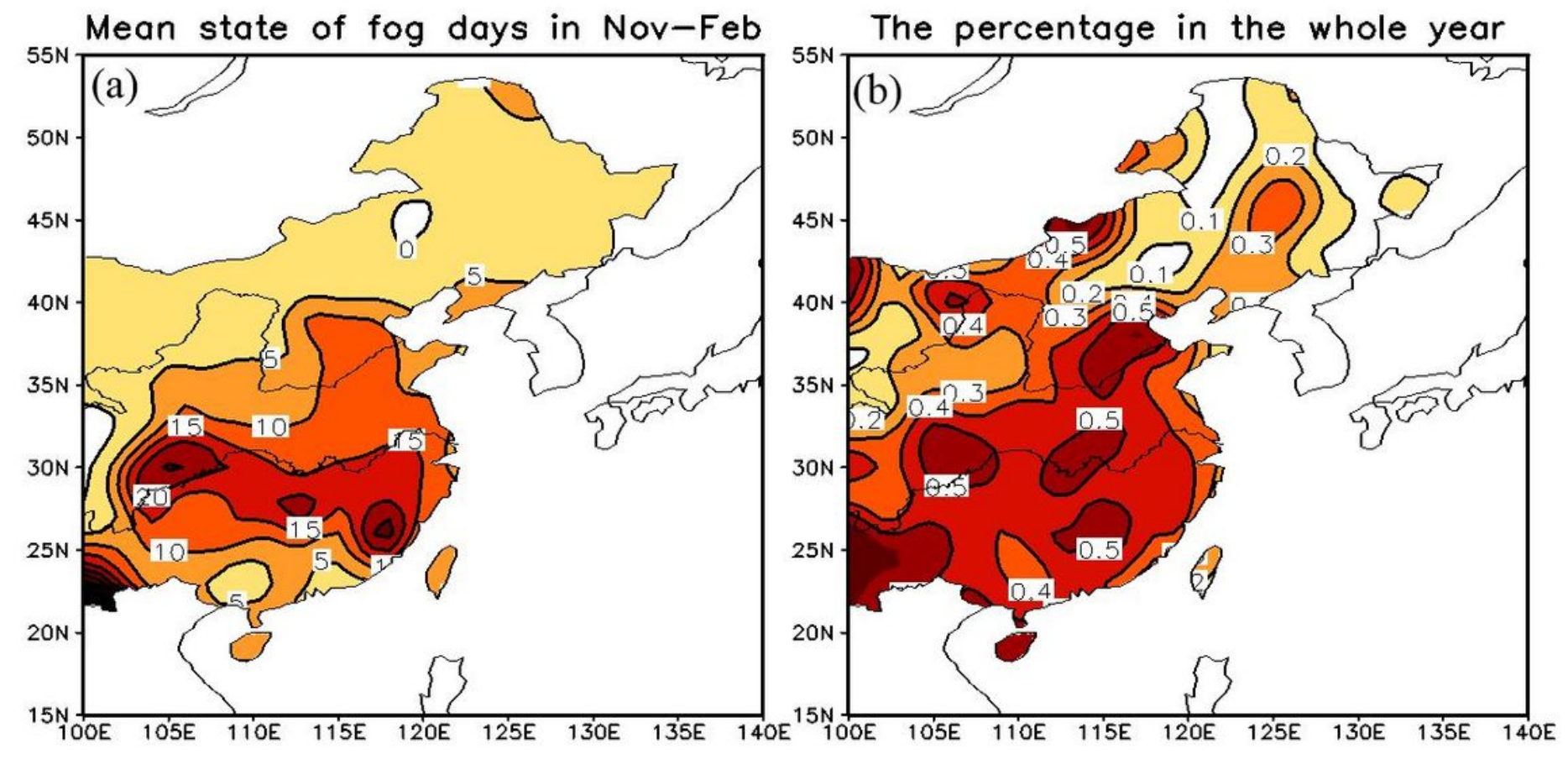

\section{Figure 1}

(a) Climatology of winter (Nov-Feb) fog days in eastern China during 1954-2007 (unit: day). (b) The ratio of winter (Nov-Feb) fog days to the annual average. Note: The designations employed and the presentation of the material on this map do not imply the expression of any opinion whatsoever on the part of Research Square concerning the legal status of any country, territory, city or area or of its authorities, or concerning the delimitation of its frontiers or boundaries. This map has been provided by the authors. 

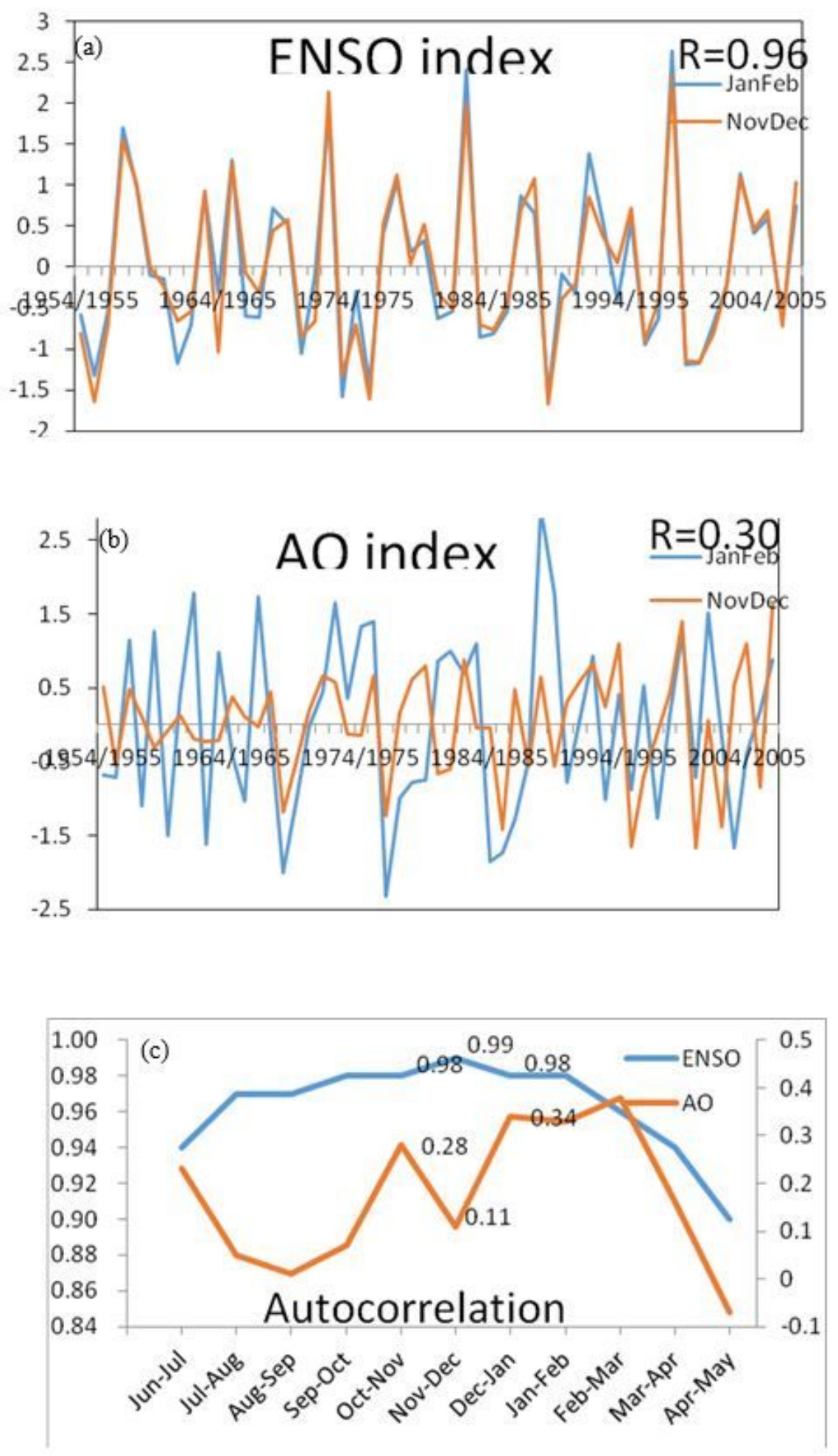

Figure 2

(a) ENSO wintertime index. (b) AO wintertime index in ND (yellow lines) and in JF (blue lines) during 1954-2007. (c) Monthly autocorrelation of ENSO (blue lines) index and AO (yellow lines) index during 1954-2007 (the right y-axis and left y-axis are the ENSO and AO autocorrelation coefficients, respectively). 

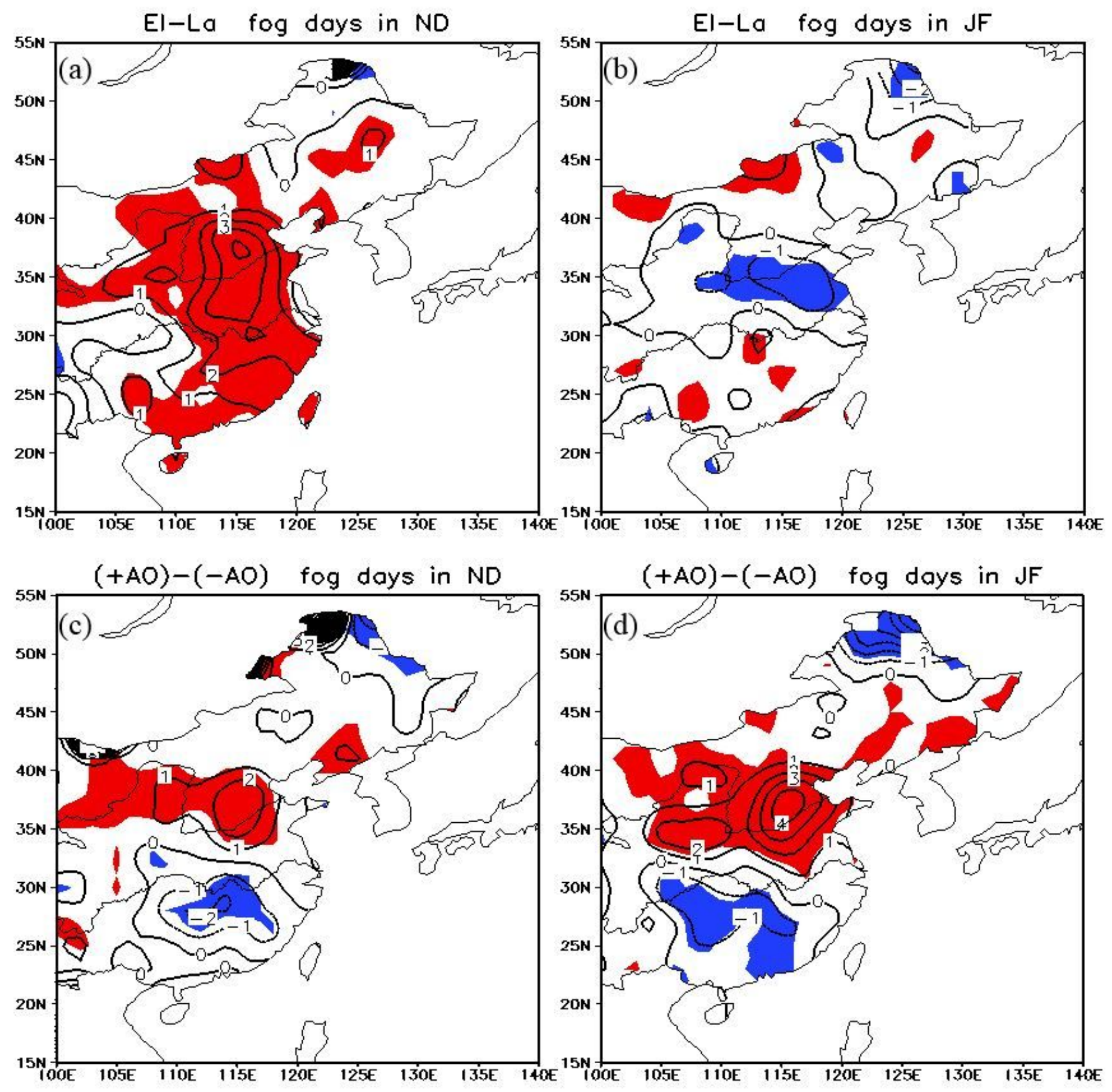

Figure 3

The difference of composite fog days between El Niño and La Niña years in (a) ND and (b) JF. (c) and (d)) are the same as (a) and (b) except for between $+A O$ and $-A O$ years. Shading represents the values exceeding the $90 \%$ confidence level. 

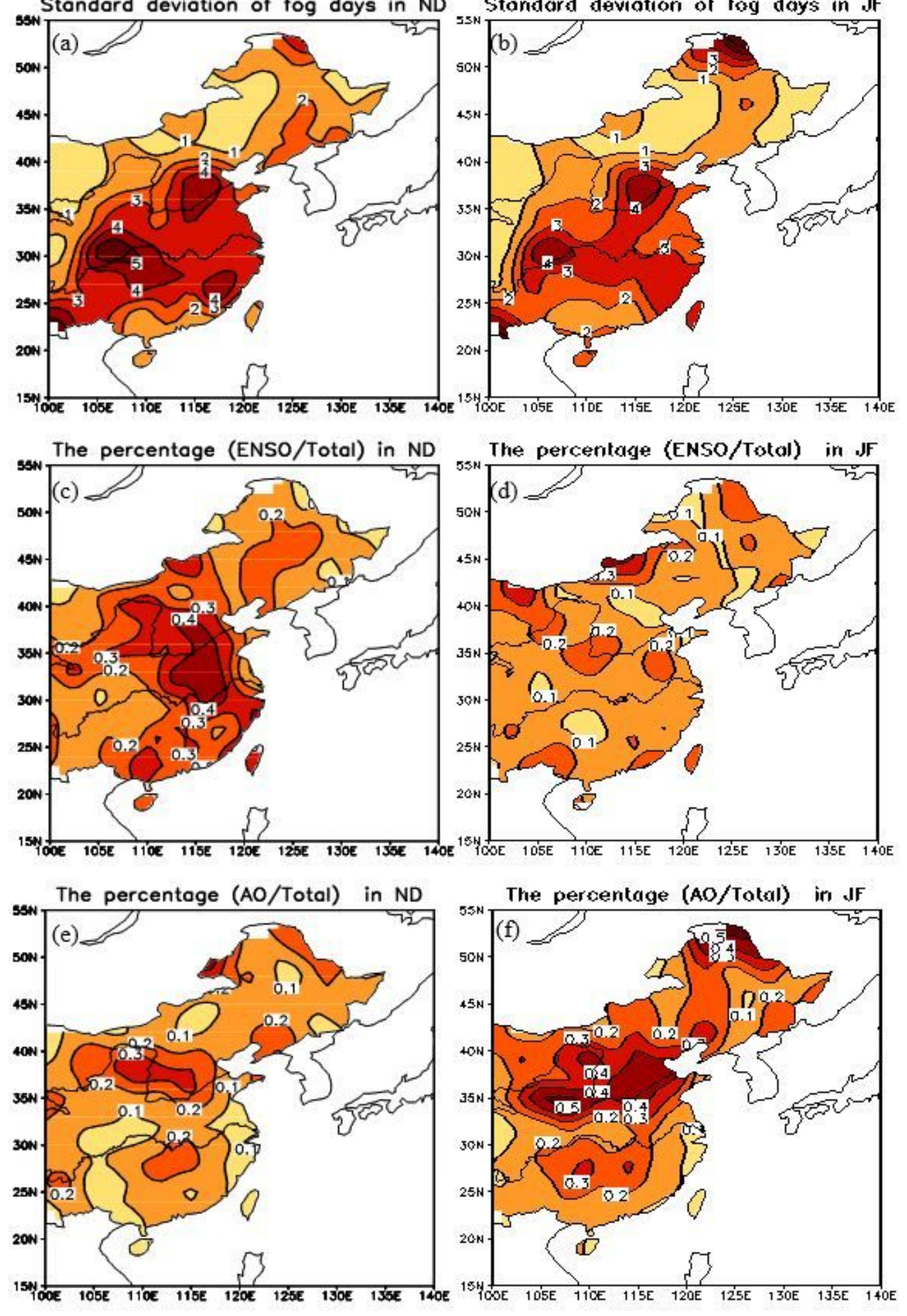

\section{Figure 4}

The standard deviation distribution (unit: day) of winter fog days in eastern China in (a) ND and (b) JF during 1954-2007, and the ratio of ENSO fog days to the total variability of fog days in (c) ND and (d) JF. (e) and (f) are the same as (b) and (c) except for AO fog days. Note: The designations employed and the presentation of the material on this map do not imply the expression of any opinion whatsoever on the part of Research Square concerning the legal status of any country, territory, city or area or of its 
authorities, or concerning the delimitation of its frontiers or boundaries. This map has been provided by the authors.
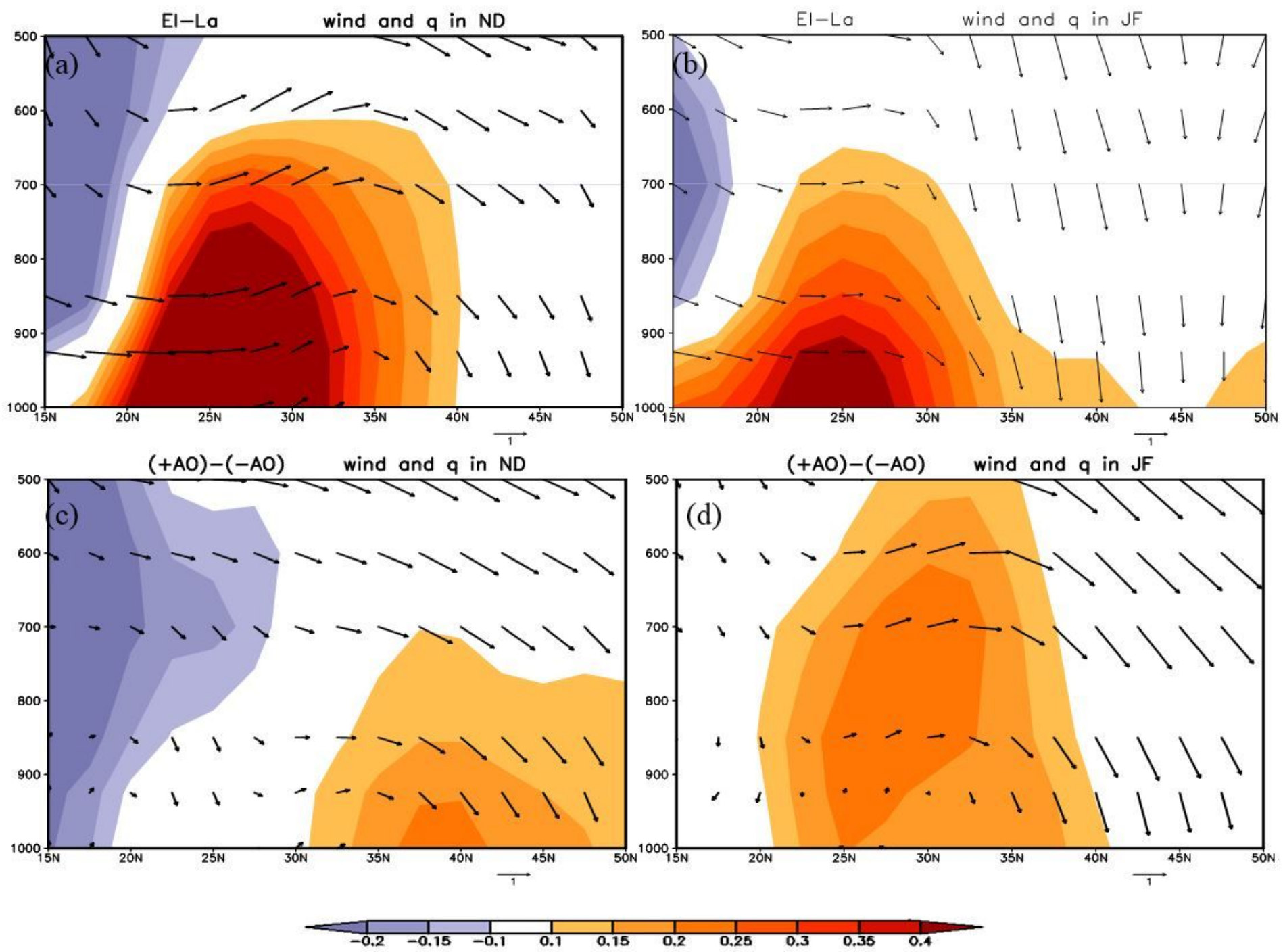

\section{Figure 5}

Meridional-vertical cross sections $\left(110^{\circ}-120^{\circ} \mathrm{E}\right)$ of the composite wind (vector; unit of $\mathrm{v}$ : $\mathrm{m} / \mathrm{s}$; unit of $\omega$ : $-0.02 \mathrm{~Pa} / \mathrm{s}$, anomalous $\omega$ superimposed on climate state $\omega$ ) and specific-humidity difference (shading; unit: $\mathrm{g} / \mathrm{kg}$ ) between El Niño and La Niña years in (a) ND and (b) JF. (c) and (d) are the same as (a) and (b) except for between $+\mathrm{AO}$ and $-\mathrm{AO}$ years. 

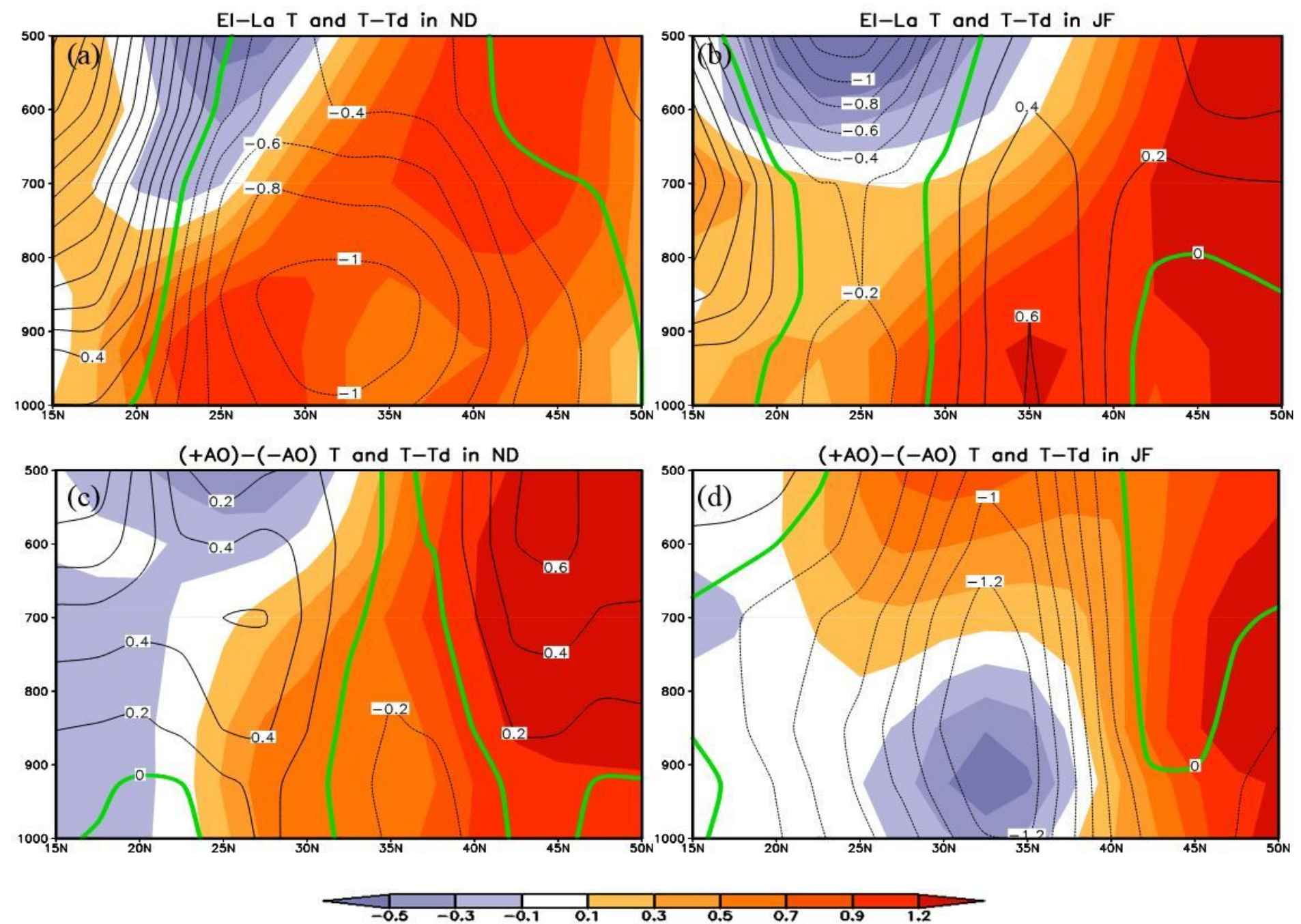

\section{Figure 6}

Composite meridional-vertical cross sections $\left(110^{\circ}-120^{\circ} \mathrm{E}\right.$ ) of the $\mathrm{T}$ (shading; unit: $\mathrm{K}$ ) and $\mathrm{T}-\mathrm{Td}$ (contour line, unit: K, green line: zero value) difference between El Niño and La Niña years in (a) ND and (b) JF. (c) and (d) are the same as (a) and (b) except for between $+A O$ and -AO years. 

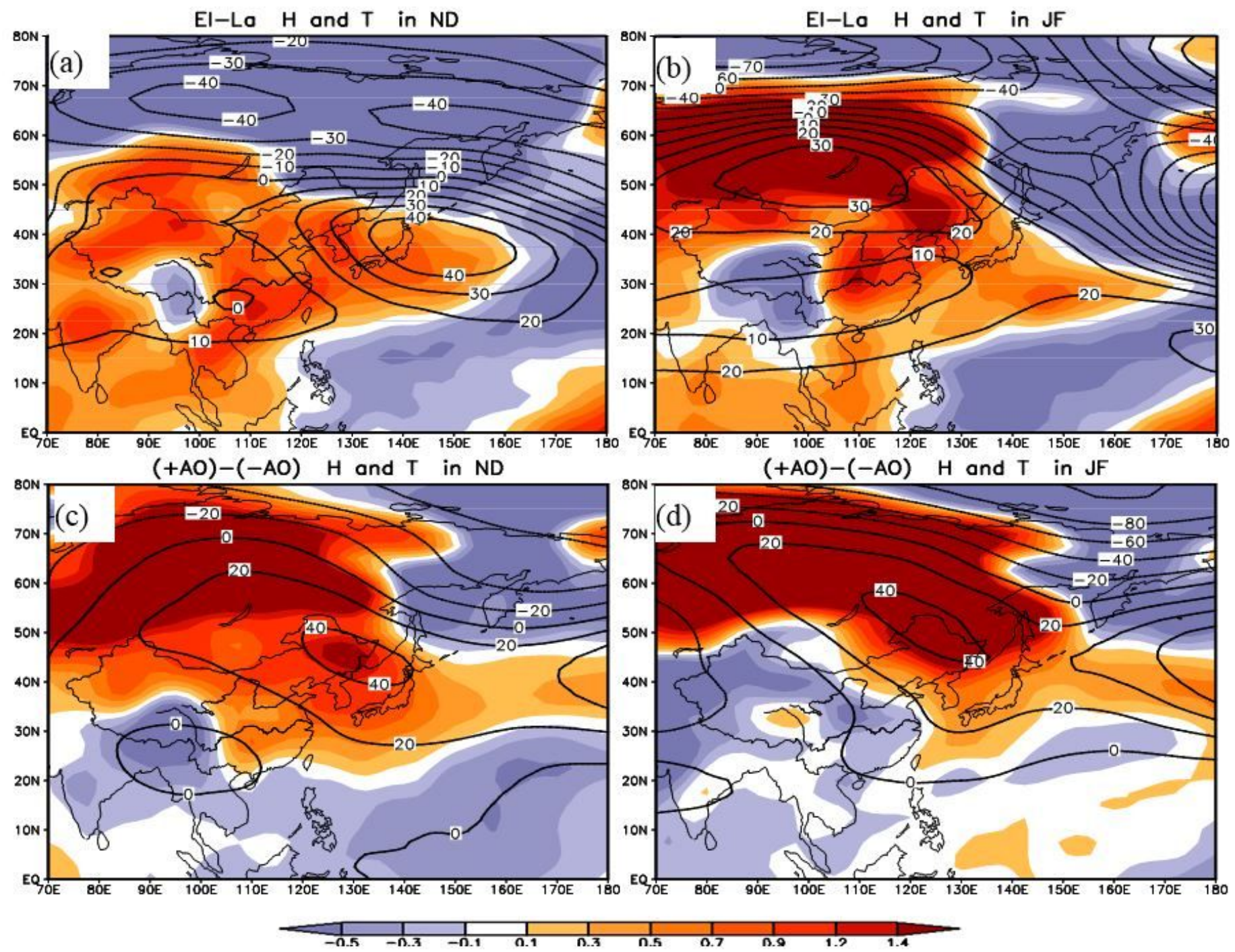

\section{Figure 8}

The difference of composite $500 \mathrm{hPa}$ height and T anomaly (shaded) between El Niño and La Niña years in (a) ND and (b) JF (contour, unit: gpm; shading, unit: K). (c) and (d) are the same as (a) and (b) except for between $+A O$ and $-A O$ years. 

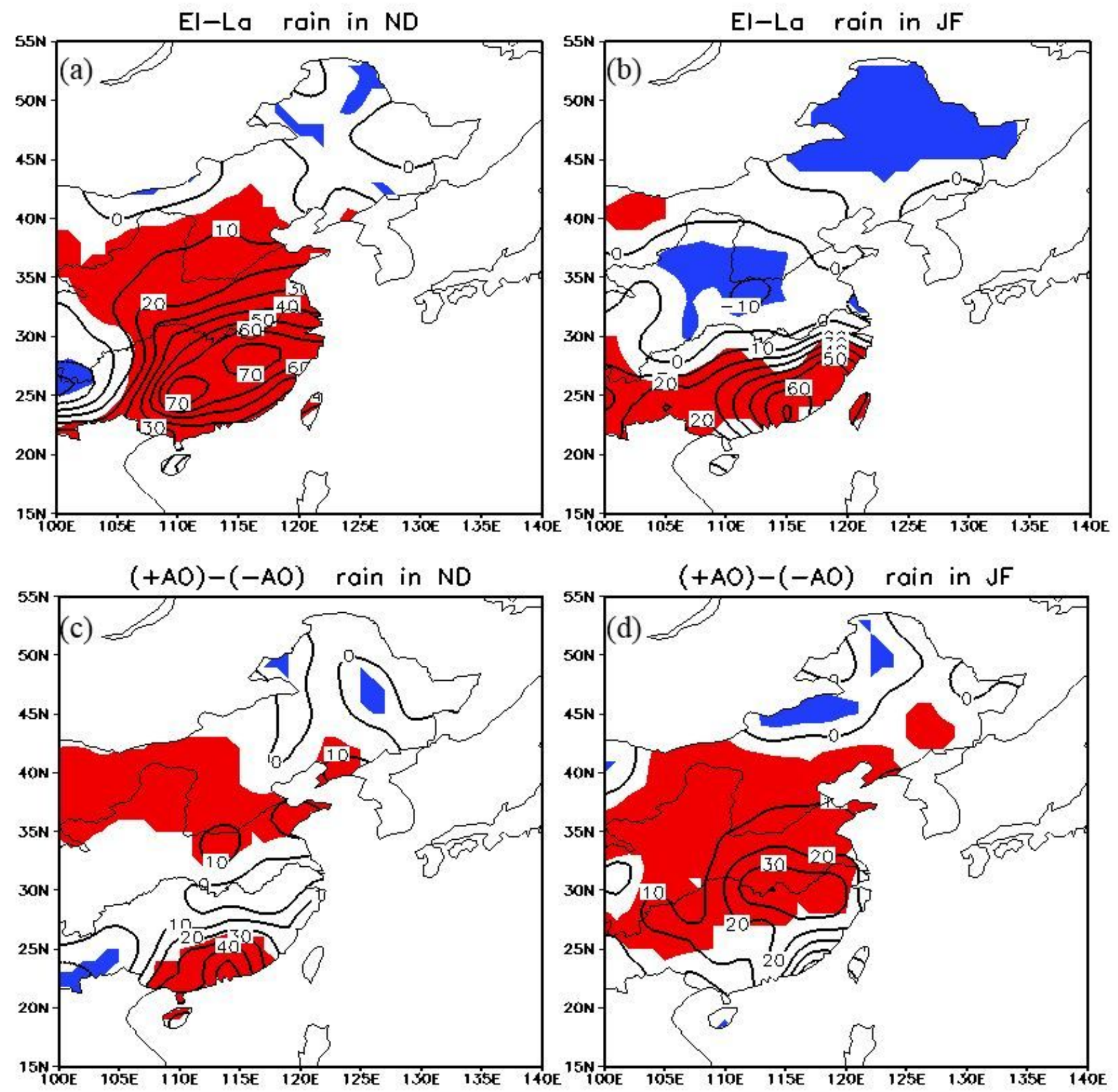

\section{Figure 9}

The difference of composite rainfall anomaly between El Niño and La Niña years in (a) ND and (b) JF (solid, unit: mm/month). (c) and (d) are the same as in (a) and (b) except for between +AO and -AO years. Shading represents the values exceeding the $90 \%$ confidence level. 

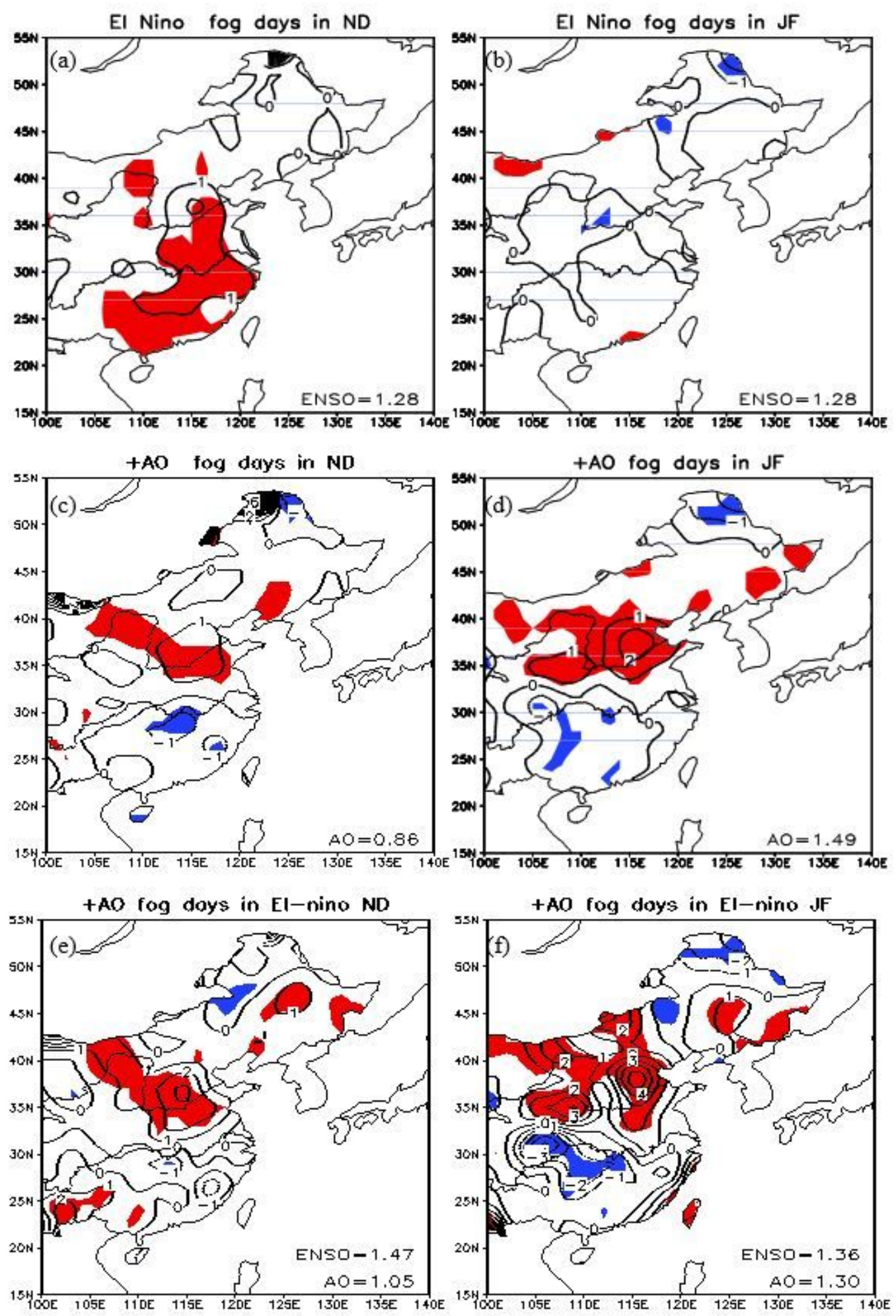

\section{Figure 10}

Composite of anomalous fog days over eastern China in (a) ND and (b) JF during El Nino years, respectively. (c) and (d) are the same as (a) and (b) except for during +AO years. (e) and (f) are the same as (a) and (b) except for both $+\mathrm{AO}$ and El Nino years. Shading represents the values exceeding the $90 \%$ confidence level. Note: The designations employed and the presentation of the material on this map do not imply the expression of any opinion whatsoever on the part of Research Square concerning the legal 
status of any country, territory, city or area or of its authorities, or concerning the delimitation of its frontiers or boundaries. This map has been provided by the authors.
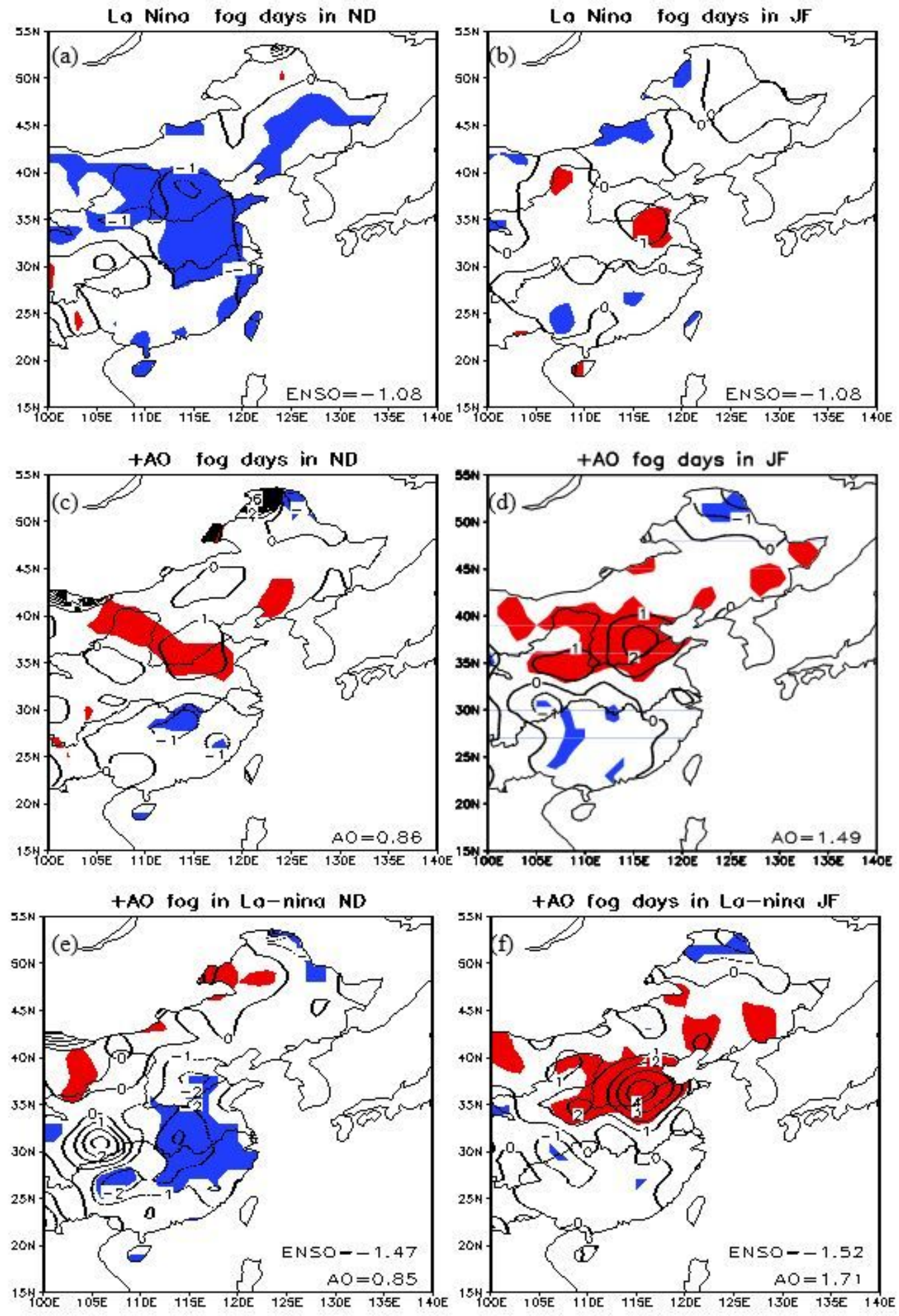

Figure 11

Composite of anomalous fog days over eastern China in (a) ND and (b) JF during La Nina years, respectively. (c) and (d) are the same as (a) and (b) except for during +AO years. (e) and (f) are the same as (a) and (b) except for both +AO and La Nina years. Shading represents the values exceeding the $90 \%$ 
confidence level. Note: The designations employed and the presentation of the material on this map do not imply the expression of any opinion whatsoever on the part of Research Square concerning the legal status of any country, territory, city or area or of its authorities, or concerning the delimitation of its frontiers or boundaries. This map has been provided by the authors.
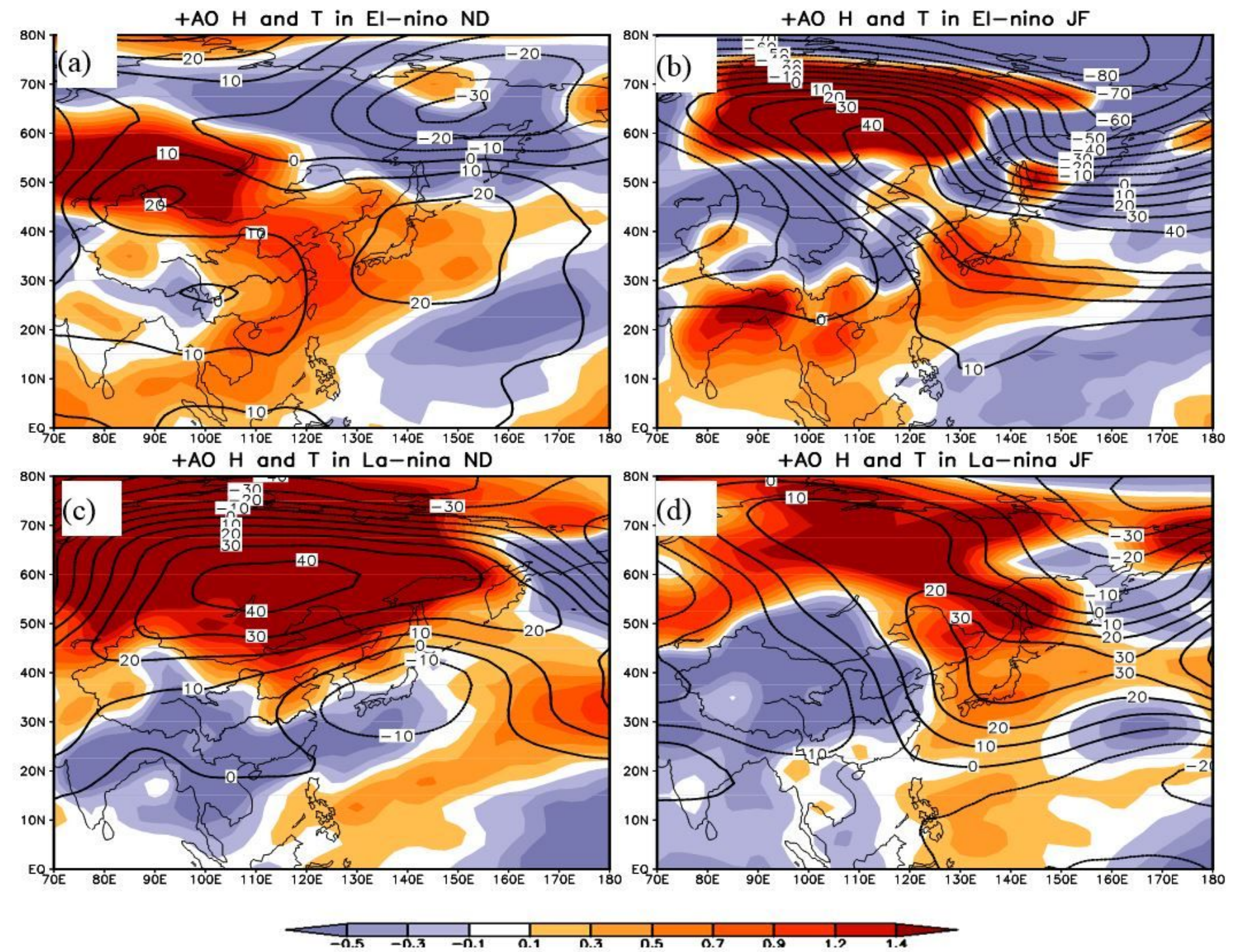

Figure 12

The same as Fig.8, but (a) and (b) are for both +AO and El Nino years in ND and JF, respectively. (c) and (d) are both $+\mathrm{AO}$ and La Nina years in ND and JF, respectively. 

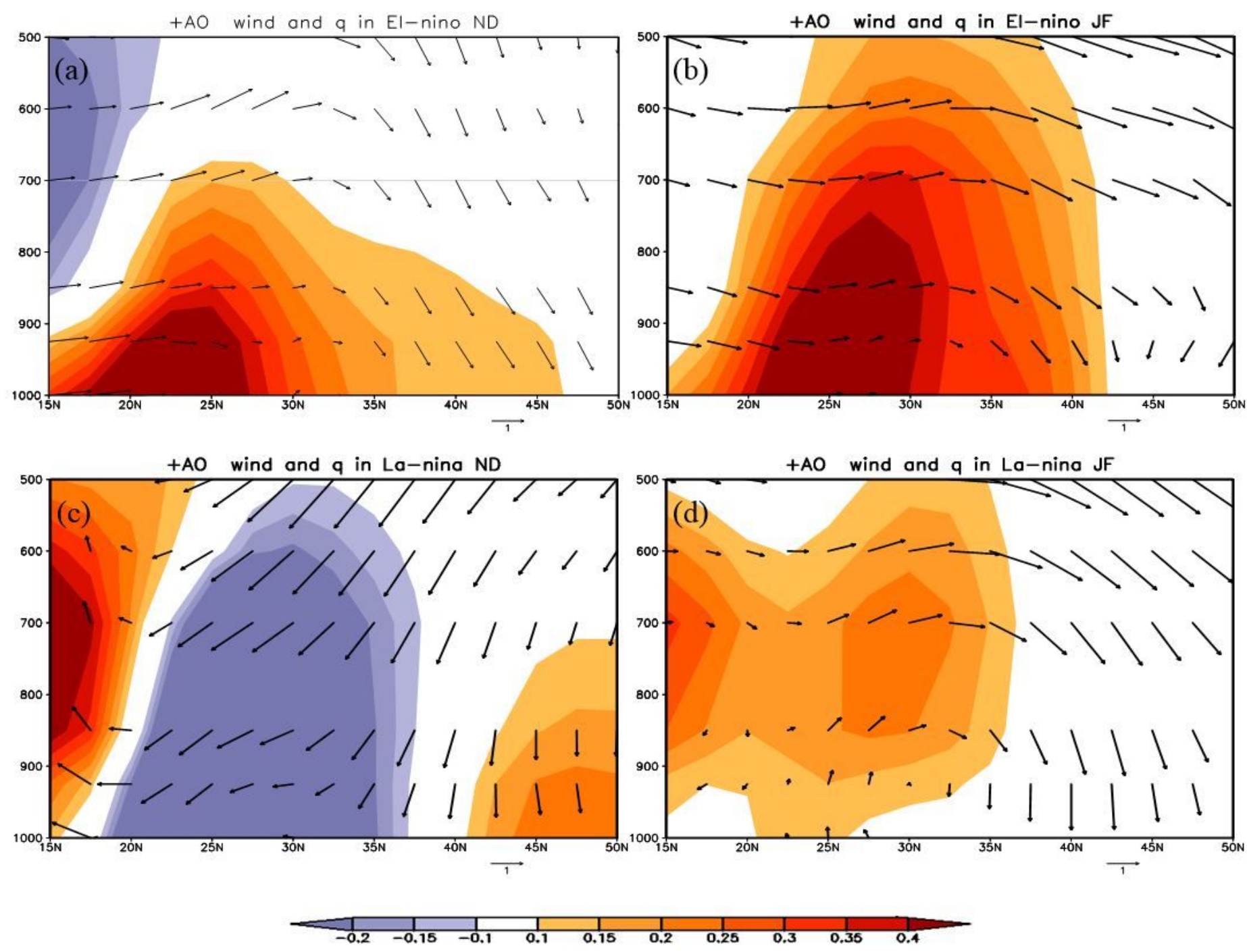

Figure 13

The same as Fig.5, but (a) and (b) are for both +AO and El Nino years in ND and JF, respectively. (c) and (d) are for both $+\mathrm{AO}$ and La Nina years in ND and JF. 

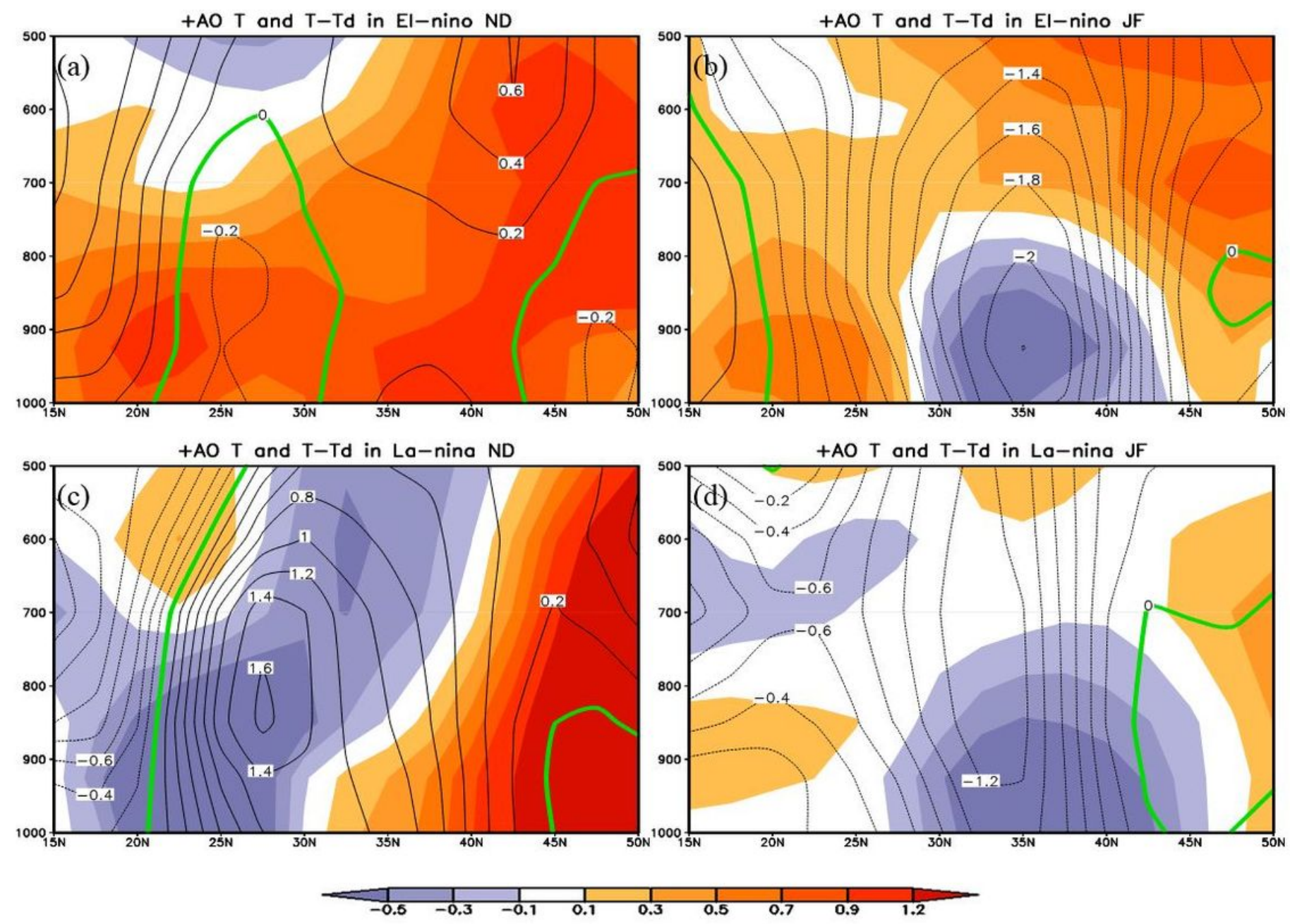

\section{Figure 14}

The same as Fig.6, but (a) and (b) are for both +AO and El Nino years in ND and JF, respectively. (c) and (d) are for both $+\mathrm{AO}$ and La Nina years in ND and JF, respectively. 

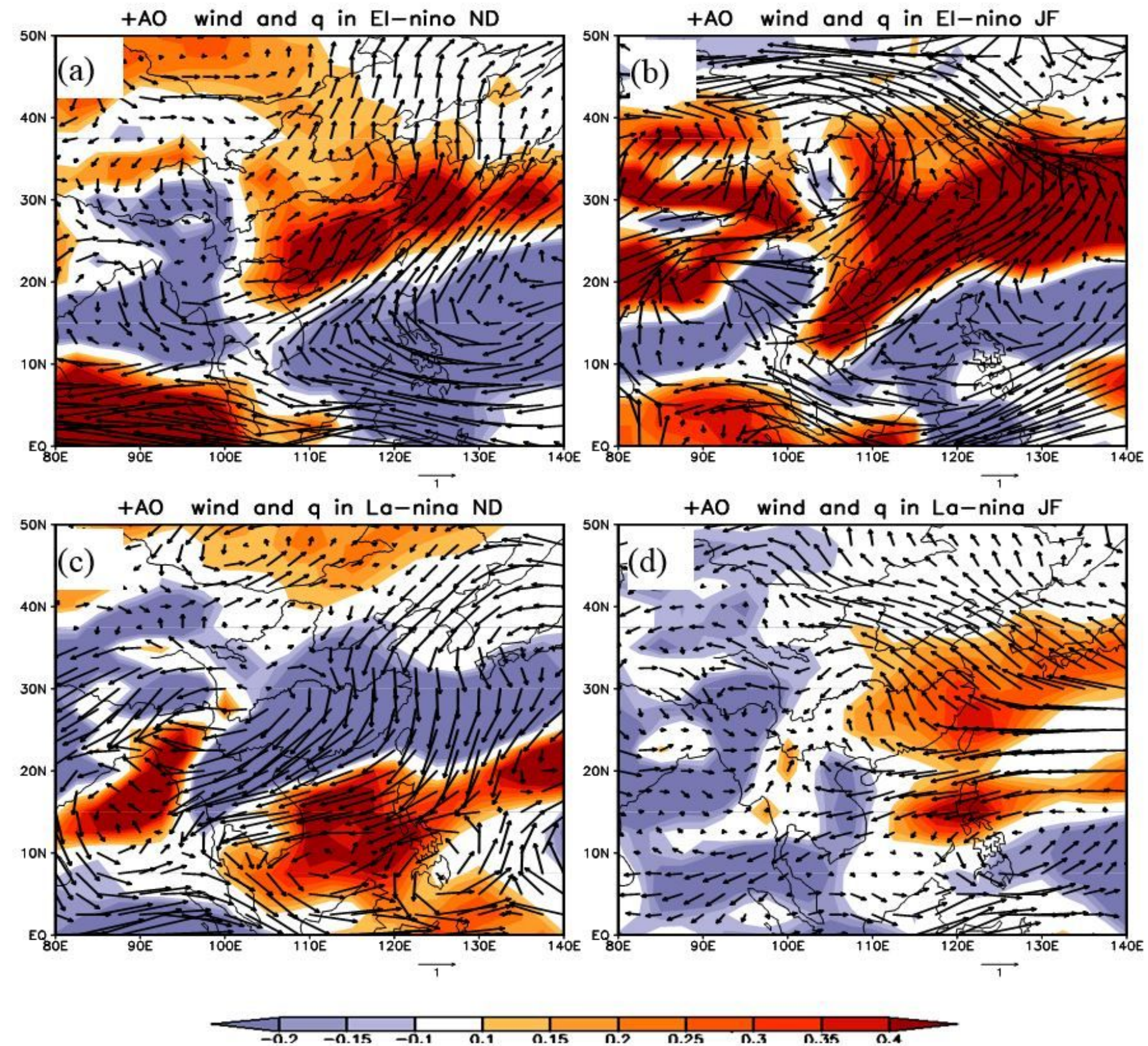

Figure 15

The same as Fig.7, but (a) and (b) are for both +AO and El Nino years in ND and JF, respectively. (c) and (d) are for both $+\mathrm{AO}$ and La Nina years in ND and JF. 